Asia-Pacific Joumal of

Clinical

Oncology

\title{
Effect of statin and aspirin use on toxicity and pathological complete response rate of neo-adjuvant chemo-radiation for rectal cancer
}

\begin{tabular}{|c|c|}
\hline Journal: & Asia-Pacific Journal of Clinical Oncology \\
\hline Manuscript ID & APJCO-2015-0363.R1 \\
\hline Manuscript Type: & Original Article \\
\hline Date Submitted by the Author: & $16-$ Oct-2015 \\
\hline Complete List of Authors: & $\begin{array}{l}\text { Hardie, Claire; MidCentral District Health Board, Regional Cancer } \\
\text { Treatment Service } \\
\text { Jameson, Michael; Waikato Hospital, Oncology } \\
\text { Jung, Yoonsuh; University of Waikato, Department of Statistics }\end{array}$ \\
\hline Keywords: & $\begin{array}{l}\text { medical oncology < Group 1: Major Specialty, radiation oncology < Group } \\
\text { 1: Major Specialty, ..colorectal < gastrointestinal cancers < Group 2: } \\
\text { Tumor Type }\end{array}$ \\
\hline
\end{tabular}




\section{Effect of statin and aspirin use on toxicity and pathological complete response rate of neo-adjuvant chemo-radiation for rectal cancer}

Running title: Statin use in rectal cancer chemo-radiation

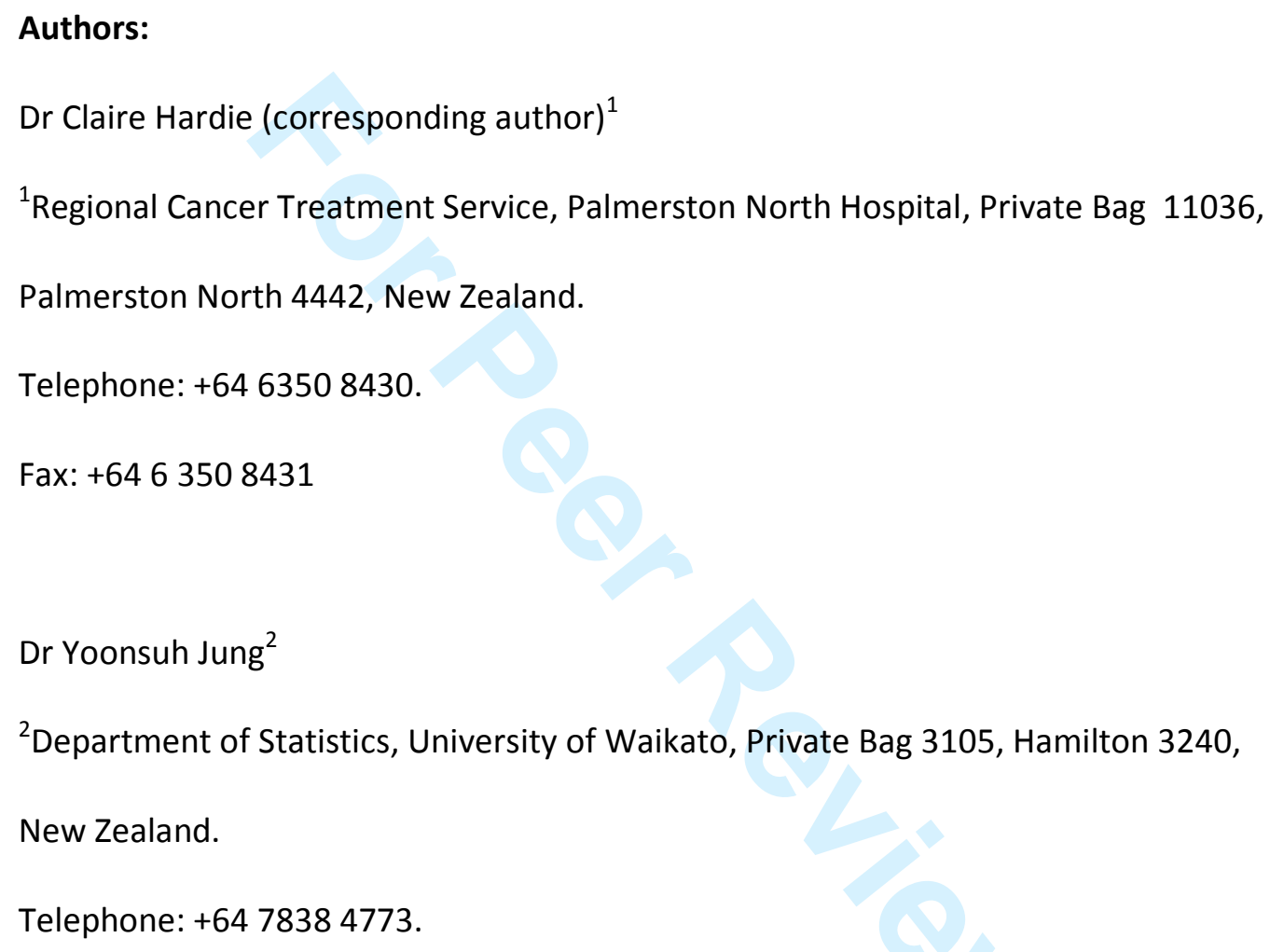




\begin{abstract}
Aims: To retrospectively evaluate the potential impact of statin and aspirin use on acute toxicity and pathological complete response rate ( $\mathrm{PCR}$ ) in rectal cancer patients receiving neo-adjuvant long course radiation (LCRT) with concurrent chemotherapy.
\end{abstract}

Methods: A retrospective review was performed of all patients undergoing neoadjuvant LCRT for rectal adenocarcinoma at the Regional Cancer Treatment Service between 1 September 2007 and 1 June 2011. Data obtained include demographic details; date and radiological TNM stage at diagnosis; medication taken at time of radiation therapy; toxicity during LCRT; and surgical histology to determine if a PCR was obtained following LCRT.

Results: Neo-adjuvant LCRT was administered to 142 patients for rectal cancer during this period; concurrent chemotherapy was omitted in 13 due to significant comorbidities. TNM stage was 2 or 3 radiologically at diagnosis in 127 (89.4\%) of patients. At the time of LCRT $23 \%$ were taking a statin and $25 \%$ were taking aspirin. Of 135 assessable patients, 34 (13\%) achieved a pCR at surgery. On logistic regression $\mathrm{pCR}$ was not significantly associated with the use of chemotherapy, statins, aspirin, other NSAIDs, T-stage or N-stage. There was no significant correlation between statin or aspirin use with bladder or rectal toxicity. Actuarial time to maximum rectal toxicity was not different in statin users or non-users. 
Conclusion: In contrast to other larger retrospective series, this study did not find improvements in toxicity or $\mathrm{pCR}$ rate through statin or aspirin use in rectal cancer patients undergoing LCRT. Their potential benefits in this setting would be best studied prospectively in a large randomised trial.

Keywords: chemo-radiation; rectal cancer; statin; aspirin 


\section{Introduction}

While advances in the management of rectal cancer have reduced local relapse to less than $10 \%$ in most patients, those with TNM tumour stage T4 and higher-risk T3 node-positive tumours still have higher local relapse rates. In addition, distant relapse still occurs in $25-30 \%$, with a similar proportion dying within 5 years (1). Statins are a class of drugs that inhibit the mevalonate pathway through inhibition of the rate-controlling enzyme, 3-hydroxy-3-methyl-glutaryl-CoA reductase. While they are commonly used to lower cholesterol, it appears that modulation of this signalling pathway may also improve cancer outcomes (2). A Danish population study of 295,925 cancer cases diagnosed between 1995 and 2007 revealed that the use of statins significantly improved overall survival (OS) in the whole cohort, and specifically within the colorectal cancer (CRC) group (HR 0.79, 95\% Cl 0.74-0.85) (3). Similarly a registry study of 17,115 CRC patients from Taiwan reported that multivariate cancer-specific mortality was significantly reduced in statin users (HR $0.77, p<0.001)(4)$. More recently a population-based cohort study of 7657 patients with CRC in the United Kingdom showed that statin use improved CSS (fully adjusted $\mathrm{HR}, 0.71 ; 95 \% \mathrm{Cl}, 0.61$ to 0.84 ) and all-cause mortality (fully adjusted HR, $0.75 ; 95 \%$ $\mathrm{Cl}, 0.66$ to 0.84$)(5)$.

Preclinical studies have elaborated mechanisms that may contribute to improved cancer outcomes with statins, many of which relate to effects on cell signalling that are independent of cholesterol metabolism (6). These include mechanisms that can improve treatment efficacy as well as inhibition of radiation (RT)-induced gut and 
skin toxicities (7-14). Thus there appears to be a specific and beneficial interaction of statins with RT.

This correlates with retrospective clinical studies in which patients taking statins during chemo-RT for rectal cancer at Memorial Sloan-Kettering Cancer Center ( $n=349)$, Cleveland Clinic ( $n=407)$ or 5 Canadian hospitals $(n=891)$ had significantly higher rates of pathological complete response ( $p C R$ ) on multivariate analysis, ranging from 1.7 to 4.5 (15-17). In contrast no benefit from statin use was seen in a large trial ( $n=842$ ) of adjuvant chemotherapy for colon cancer (18). Furthermore, a prospective observational study of 308 patients at the Royal Marsden Hospital, London, treated with radical pelvic RT reported that those taking statins had significantly reduced RT-induced bowel toxicity, both during treatment $(p=0.04)$ and one year later (19).

Aspirin's inhibition of platelet activation, platelet-tumour cell adhesion, angiogenesis and metastasis, as well as therapeutic interactions with chemotherapy and RT, have demonstrated survival benefits in CRC patients in some series (20-23) though not all (24). Interestingly, even though statins and aspirin may both improve outcomes through inhibiting inflammation, the benefit of statins is still seen when controlling for aspirin use (4)

We retrospectively explored the potential benefit of using statin and/or aspirin or other non-steroidal anti-inflammatory drugs (NSAIDs) in the clinical setting of rectal 
cancer patients receiving a standard course of neo-adjuvant long-course radiation therapy (LCRT) with concurrent chemotherapy (chemo-RT). We report the association of the use of statins and NSAIDS in this patient group with the acute toxicity of their treatment and the pCR rate found at the time of surgery.

\section{Methods}

The electronic oncology notes were reviewed of all patients diagnosed with rectal cancer between $1^{\text {st }}$ September 2007 and $1^{\text {st }}$ June 2011 who underwent LCRT for rectal cancer at the Regional Cancer Treatment Service (RCTS), Palmerston North Hospital. Hospital paper notes were reviewed when the electronic record was incomplete. Data was obtained regarding patient's demographic details; date and radiological TNM stage at diagnosis; medication taken at time of radiation therapy; toxicity during LCRT; and surgical histology to determine if a pCR was obtained following LCRT. While the names of any statins and NSAIDs used during treatment was recorded, due to the retrospective nature of this study the details on dosage, duration of use and indication for these drugs were not available to the investigators.

The electronic oncology notes prospectively recorded weekly toxicity evaluation (graded according to the Common Toxicity Criteria Version 3.0 (25)) during LCRT, hospital admissions or if treatment was stopped early due to toxicity. For the purposes of this study, the most severe bowel and bladder toxicity that developed during radiation treatment was documented. 
LCRT was offered to all patients who were node-positive on MRI staging of their rectal cancer and/or had a threatened circumferential resection margin. LCRT was also considered if the surgeon felt resection would be difficult due to tumour bulk. LCRT was delivered as a 3D conformal technique using $15 \mathrm{MV}$ photons in 2 phases: phase 1 delivered a dose of 45 Gray (Gy) in 25 fractions over 5 weeks to the pelvis; phase 2 delivered a boost dose to the rectal tumour of 5.4 Gy in 3 fractions over 3 days. Concurrent chemotherapy (capecitabine $825 \mathrm{mg} / \mathrm{m}^{2}$ twice daily or continuous IV infusion of 5-fluorouracil [5FU] $225 \mathrm{mg} / \mathrm{m}^{2} /$ day) was administered with LCRT as standard practice, unless medical fitness or co-morbidities precluded this (in some of these patients bolus $5 \mathrm{FU}$ was given at a dose of $500 \mathrm{mg} / \mathrm{m}^{2}$ on days $1-5$ of week 1 and week 5 of radiation treatment). On completion of LCRT, definitive surgery (either total mesorectal excision or abdomino-perineal resection) took place $6-8$ weeks later.

Statistical analysis of this dataset was undertaken using Spearman correlation between patient, tumour and treatment parameters and toxicity and pCR rate. Logistic regression was used to evaluate the association of statin, aspirin, other NSAIDs or chemotherapy use on pCR rate, rectal toxicity grade and time to maximum toxicity. Actuarial analysis of time to maximum rectal toxicity was analysed using the Kaplan-Meier method and log-rank statistic. Under the significance level of 0.05 and two-sided testing, $p<0.05$ is assumed to be statistically significant.

\section{Results}


Between $1^{\text {st }}$ September 2007 and $1^{\text {st }}$ June 2011, 142 patients were diagnosed with rectal cancer and received LCRT at RCTS. Patient demographics of this group are outlined in Table 1. Concurrent chemotherapy was given to 129 (91\%) patients (106, 16 and 7 with capecitabine, infusional and bolus 5FU respectively); 13 did not receive concurrent chemotherapy due to co-morbidities. Eleven patients $(7.7 \%)$ were known to have metastatic disease at the time of diagnosis, of which nine had concurrent chemo-RT. Thirty three (23\%) patients were taking a statin at the time of their LCRT (see Table 2), 28 using simvastatin and 5 using atorvastatin. Thirty-five (25\%) patients were taking aspirin, 7 (5\%) were taking other NSAIDs and 19 (13\%) patients were taking both a statin and aspirin.

After completion of LCRT, only 140 patients went on to surgery as 2 patients died prior to their surgical procedure. In a further 5 patients the histological report was not obtainable and in all these cases their surgery was performed at a peripheral hospital. Of the 135 assessable patients, 17 (13\%) achieved a pCR at the time of surgery. On logistic regression pCR was not significantly associated with the use of chemotherapy, statins, aspirin, other NSAIDs, T-stage or N-stage.

Prospectively-recorded data was available on bladder and rectal toxicity during RT in 141 patients. The most severe toxicity recorded was grade 3 for both bladder and rectum, in 1 and 19 (13.5\%) patients respectively. Grade 1 and 2 bladder toxicities were recorded in 62 (44\%) and 21 (14.9\%) patients respectively, and grade 1 and 2 rectal toxicities in $40(28.4 \%)$ and $72(51.1 \%)$ patients respectively (Table 2$)$. Of the 129 patients who received concurrent chemotherapy, this treatment had to be 
discontinued during RT in 47 (36\%) due to toxicity and 15 patients (12\%) were hospitalised for toxicity during treatment. RT was stopped earlier than scheduled in 7 patients (5\%) due to toxicity.

Univariate analysis was performed of correlations between the following parameters: age (as a continuous variable); tumour grade; $\mathrm{T}-, \mathrm{N}$ - and $\mathrm{M}$-stage; use of chemotherapy, statins, aspirin or other NSAIDs; time to, and maximum grade of bladder or rectal toxicity; early cessation of chemotherapy or RT; and pCR. A significant correlation was seen between age and statin $(r=0.19)$ or aspirin $(r=0.29)$ use and an inverse correlation with chemotherapy use $(r=-0.38)$ and $N$-stage $(r=-$ 0.24; all $p<0.05)$. Patients taking statins also had significantly lower $\mathrm{N}$-stage $(r=-$ 0.23 ) and those who received chemotherapy had significantly lower T-stage ( $r=-$ 0.21). Grade of rectal toxicity was significantly associated with early cessation of chemotherapy $(r=0.42)$.

There was no significant correlation between statin or aspirin use with bladder or rectal toxicity (Figure 1). Multinomial logistic regression was used to evaluate associations with grade of rectal toxicity: no interaction was seen with statin, aspirin or NSAID use, whereas chemotherapy was strongly associated with grade 3 toxicity (coefficient 15.3, $p<0.00001$ ). Actuarial time to maximum rectal toxicity was not different in statin users or non-users, when analysing either all patients (log-rank $p=0.78)$ or those who had at least grade 2 toxicity (log-rank $p=0.44$, Figure 2$)$.

\section{Discussion}


We undertook this retrospective study to specifically evaluate the effect of statins and aspirin on acute treatment toxicity and $\mathrm{pCR}$ rates in rectal cancer patients being treated with neo-adjuvant LCRT, with or without concurrent chemotherapy. This was inspired by reports from other groups, in larger datasets, that statins appeared to reduce the acute toxicity of treatment and increased the pCR rate $(15-17 ; 19)$, while statins and aspirin were each associated with improved overall colorectal cancer outcomes (3;22). In this cohort of 142 patients, about a quarter of whom took either agent ( $13 \%$ took both), we were unable to demonstrate a significant benefit in either acute treatment-related toxicity or pCR rate from statin or aspirin use. In contrast, adding chemotherapy to LCRT substantially increased the severity of toxicity, consistent with other reports (26), though in this series we did not see the improved histological outcome reported by others (27).

While large population studies suggest that statins improve relapse and cancerspecific survival in various cancers including rectal cancer $(3 ; 4 ; 28-30)$, there appear to be beneficial interactions with RT that are not apparent with other treatments. Retrospective clinical studies report that patients taking statins during RT or chemoRT for rectal, bladder or prostate cancer had significantly higher rates of pathological complete response (pCR), local control and PSA progression-free survival, respectively (15-17;31-33). In contrast no benefit from statin use was seen in a meta-analysis of surgical treatment of prostate cancer $(31 ; 33)$ nor adjuvant chemotherapy for colon cancer (18). However, in a large breast cancer population the significantly-reduced relapse risk associated with statin use did not appear to 
differ by specific cancer treatments, including RT, chemotherapy or endocrine therapy (29).

Mechanisms that may contribute to improved cancer outcomes with statins relate either to direct effects on tumours (including generation of pro-apoptotic, growthinhibitory and pro-differentiation responses, radiosensitisation of tumour cells and inhibition of angiogenesis, invasion and metastasis) or to effects on normal tissues (reducing inflammation and inhibiting RT-induced intestinal and skin toxicities) (813). Statins can modify the acute RT-related normal tissue inflammatory response through inhibiting endothelial cell damage and activation, thus preventing recruitment of inflammatory cells into the tissues $(11 ; 12 ; 34 ; 35)$, with reduced late toxicities (and acute toxicities to a lesser extent) reported in preclinical models $(12 ; 13 ; 36)$. A solitary prospective observational study evaluating this in patients receiving radical pelvic $\mathrm{RT}$ showed statins significantly reduced $\mathrm{RT}$-induced bowel toxicity, both during treatment and one year later (19).

On the background of this significant body of preclinical and clinical work supporting potential clinically-significant benefits of statin use during RT, the lack of benefit in toxicity or PCR rate with statins found in this retrospective study is most likely due to its significant limitations. This single centre study has a small sample size and it was not possible retrospectively to collect data on ECOG performance status or other factors such as pre-treatment CEA levels which have been associated with higher odds ratios for $\mathrm{pCR}$ (17). Similarly we were not able to evaluate a possible 
interaction between dose or duration of aspirin or statin use, nor the late toxicity of treatment and disease outcome data. We also acknowledge that the logistic regression analysis of the $\mathrm{pCR}$ rate and its association with other factors, including aspirin and statin use, will be limited by the small number of events $(n=17)$.

Our results are also consistent with the possibility of there being no beneficial interaction of statins with RT in rectal cancer patients, or indeed for colon or rectal cancer overall, as reported by other authors $(18 ; 37)$. Larger patient numbers than those we evaluated in this study are needed to discriminate the influence of statins and NSAIDS on treatment toxicities and outcomes separate to other prognostic variables. The true benefits of statins in this clinical setting can be best evaluated with the least bias and confounding by large, prospective, well-designed, randomised, placebo-controlled trials.

\section{Conclusion}

Although our study did not find improvements in toxicity or pCR rate through statin or aspirin use in rectal cancer patients undergoing LCRT, the preclinical and clinical data collectively present a compelling case for such trials to be conducted, especially in cancer patients who are being treated with RT. Neo-adjuvant LCRT or chemo-RT in rectal cancer patients is a setting in which efficacy of statins in reducing toxicities can be combined with evaluating the histological, inflammatory and molecular effects of these agents in normal and malignant tissues. The implications of such a benefit at a population level are profound, offering improved tolerability of RT and better cancer outcomes, using agents that have very low cost and toxicity. 


\section{References:}

\section{Reference List}

(1) Ngan SY, Burmeister B, Fisher RJ, Solomon M, Goldstein D, Joseph D, et al. Randomized trial of short-course radiotherapy versus long-course chemoradiation comparing rates of local recurrence in patients with T3 rectal cancer: Trans-Tasman Radiation Oncology Group trial 01.04. J Clin Oncol 2012 Nov 1;30(31):3827-33.

(2) Corcos L, Jossic-Corcos C. Statins: perspectives in cancer therapeutics. Dig Liver Dis 2013 Oct;45(10):795-802.

(3) Nielsen SF, Nordestgaard BG, Bojesen SE. Statin use and reduced cancerrelated mortality. N Engl J Med 2012 Nov 8;367(19):1792-802.

(4) Shao YY, Hsu CH, Yeh KH, Chen HM, Yeh YC, Lai CL, et al. Statin Use Is Associated With Improved Prognosis of Colorectal Cancer in Taiwan. Clin Colorectal Cancer 2015 Feb 21;14(3):177-84.

(5) Cardwell CR, Hicks BM, Hughes C, Murray LJ. Statin Use After Colorectal Cancer Diagnosis and Survival: A Population-Based Cohort Study. J Clin Oncol 2014 Aug 4;32(28):3177-83.

(6) Bardou M, Barkun A, Martel M. Effect of statin therapy on colorectal cancer. Gut 2010 Nov;59(11):1572-85. 
(7) Gibot L, Follet J, Metges J, Auvray P, Simon B, Corcos L, et al. Human caspase 7 is positively controlled by SREBP-1 and SREBP-2. Biochem J 2009 May $27 ; 420(3): 473-83$

(8) Sassano A, Platanias LC. Statins in tumor suppression. Cancer Lett 2008 Feb $18 ; 260(1-2): 11-9$.

(9) Gazzerro P, Proto MC, Gangemi G, Malfitano AM, Ciaglia E, Pisanti S, et al. Pharmacological actions of statins: a critical appraisal in the management of cancer. Pharmacol Rev 2012 Jan;64(1):102-46.

(10) Fritz G, Brachetti C, Kaina B. Lovastatin causes sensitization of HeLa cells to ionizing radiation-induced apoptosis by the abrogation of $\mathrm{G} 2$ blockage. Int J Radiat Biol 2003 Aug;79(8):601-10.

(11) Nubel T, Damrot J, Roos WP, Kaina B, Fritz G. Lovastatin protects human endothelial cells from killing by ionizing radiation without impairing induction and repair of DNA double-strand breaks. Clin Cancer Res 2006 Feb 1;12(3 Pt 1):933-9.

(12) Holler V, Buard V, Gaugler MH, Guipaud O, Baudelin C, Sache A, et al. Pravastatin limits radiation-induced vascular dysfunction in the skin. J Invest Dermatol 2009 May;129(5):1280-91.

(13) Haydont V, Gilliot O, Rivera S, Bourgier C, Francois A, Aigueperse J, et al. Successful mitigation of delayed intestinal radiation injury using pravastatin is 
not associated with acute injury improvement or tumor protection. Int J Radiat Oncol Biol Phys 2007 Aug 1;68(5):1471-82.

(14) Follet J, Corcos L, Baffet G, Ezan F, Morel F, Simon B, et al. The association of statins and taxanes: an efficient combination trigger of cancer cell apoptosis. Br J Cancer 2012 Feb 14;106(4):685-92.

(15) Katz MS, Minsky BD, Saltz LB, Riedel E, Chessin DB, Guillem JG. Association of statin use with a pathologic complete response to neoadjuvant chemoradiation for rectal cancer. Int J Radiat Oncol Biol Phys 2005 Aug $1 ; 62(5): 1363-70$.

(16) Mace AG, Gantt GA, Skacel M, Pai R, Hammel JP, Kalady MF. Statin therapy is associated with improved pathologic response to neoadjuvant chemoradiation in rectal cancer. Dis Colon Rectum 2013 Nov;56(11):1217-27.

(17) Armstrong DE, Raissouni S, Price Hiller JA, Mercer J, Powell ED, MacLean A, et al. Predictors of pathologic complete response after neoadjuvant treatment for rectal cancer: A multicenter study. J Clin Oncol 2014 32[suppl 3], abstr 397.

(18) Ng K, Ogino S, Meyerhardt JA, Chan JA, Chan AT, Niedzwiecki D, et al. Relationship Between Statin Use and Colon Cancer Recurrence and Survival: Results From CALGB 89803. J Natl Cancer Inst 2011 Aug 17;103(20):1540-51.

(19) Wedlake LJ, Silia F, Benton B, Lalji A, Thomas K, Dearnaley DP, et al. Evaluating the efficacy of statins and ACE-inhibitors in reducing 
gastrointestinal toxicity in patients receiving radiotherapy for pelvic malignancies. Eur J Cancer 2012 Sep;48(14):2117-24.

(20) Ng K, Meyerhardt JA, Chan AT, Sato K, Chan JA, Niedzwiecki D, et al. Aspirin and COX-2 inhibitor use in patients with stage III colon cancer. J Natl Cancer Inst 2015 Jan;107(1):345.

(21) Algra AM, Rothwell PM. Effects of regular aspirin on long-term cancer incidence and metastasis: a systematic comparison of evidence from observational studies versus randomised trials. Lancet Oncol 2012 May;13(5):518-27.

(22) Rothwell PM, Wilson M, Elwin CE, Norrving B, Algra A, Warlow CP, et al. Longterm effect of aspirin on colorectal cancer incidence and mortality: 20-year follow-up of five randomised trials. Lancet 2010 Nov 20;376(9754):1741-50.

(23) Chan AT, Ogino S, Fuchs CS. Aspirin use and survival after diagnosis of colorectal cancer. JAMA 2009 Aug 12;302(6):649-58.

(24) Cardwell CR, Kunzmann AT, Cantwell MM, Hughes C, Baron JA, Powe DG, et al. Low-dose aspirin use after diagnosis of colorectal cancer does not increase survival: a case-control analysis of a population-based cohort. Gastroenterology 2014 Mar;146(3):700-8.

(25) Cancer Therapy Evaluation Program. Common Terminology Criteria for Adverse Events v3.0 (CTCAE). Bethesda, ML, USA: National Cancer Institute (USA); 2003. 
(26) Bosset JF, Collette L, Calais G, Mineur L, Maingon P, Radosevic-Jelic L, et al. Chemotherapy with preoperative radiotherapy in rectal cancer. N Engl J Med 2006 Sep 14;355(11):1114-23.

(27) Bosset JF, Calais G, Mineur L, Maingon P, Radosevic-Jelic L, Daban A, et al. Enhanced tumorocidal effect of chemotherapy with preoperative radiotherapy for rectal cancer: preliminary results--EORTC 22921. J Clin Oncol 2005 Aug 20;23(24):5620-7.

(28) Zhong S, Zhang X, Chen L, Ma T, Tang J, Zhao J. Statin use and mortality in cancer patients: Systematic review and meta-analysis of observational studies. Cancer Treat Rev 2015 Jun;41(6):554-67.

(29) Ahern TP, Pedersen L, Tarp M, Cronin-Fenton DP, Garne JP, Silliman RA, et al. Statin prescriptions and breast cancer recurrence risk: a Danish nationwide prospective cohort study. J Natl Cancer Inst 2011 Oct 5;103(19):1461-8.

(30) Ling Y, Yang L, Huang H, Hu X, Zhao C, Huang H, et al. Prognostic Significance of Statin Use in Colorectal Cancer: A Systematic Review and Meta-Analysis. Medicine (Baltimore) 2015 Jun;94(25):e908.

(31) Kollmeier MA, Katz MS, Mak K, Yamada Y, Feder DJ, Zhang Z, et al. Improved biochemical outcomes with statin use in patients with high-risk localized prostate cancer treated with radiotherapy. Int J Radiat Oncol Biol Phys 2011 $\operatorname{Mar} 1 ; 79(3): 713-8$ 
(32) Tsai HK, Katz MS, Coen JJ, Zietman AL, Kaufman DS, Shipley WU. Association of statin use with improved local control in patients treated with selective bladder preservation for muscle-invasive bladder cancer. Urology 2006 Dec;68(6):1188-92.

(33) Scosyrev E, Tobis S, Donsky H, Wu G, Joseph J, Rashid H, et al. Statin use and the risk of biochemical recurrence of prostate cancer after definitive local therapy: a meta-analysis of eight cohort studies. BJU Int 2013 Mar;111(3 Pt B):E71-E77.

(34) Nubel T, Dippold W, Kaina B, Fritz G. Ionizing radiation-induced E-selectin gene expression and tumor cell adhesion is inhibited by lovastatin and alltrans retinoic acid. Carcinogenesis 2004 Aug;25(8):1335-44.

(35) Dimitrova Y, Dunoyer-Geindre S, Reber G, Mach F, Kruithof EK, de Moerloose P. Effects of statins on adhesion molecule expression in endothelial cells. J Thromb Haemost 2003 Nov;1(11):2290-9.

(36) Haydont V, Bourgier C, Pocard M, Lusinchi A, Aigueperse J, Mathe D, et al. Pravastatin Inhibits the Rho/CCN2/extracellular matrix cascade in human fibrosis explants and improves radiation-induced intestinal fibrosis in rats. Clin Cancer Res 2007 Sep 15;13(18 Pt 1):5331-40.

(37) Hoffmeister M, Jansen L, Rudolph A, Toth C, Kloor M, Roth W, et al. Statin use and survival after colorectal cancer: the importance of comprehensive confounder adjustment. J Natl Cancer Inst 2015 Jun;107(6):djv045. 


\section{Table 1: $\quad$ Patient Demographics}

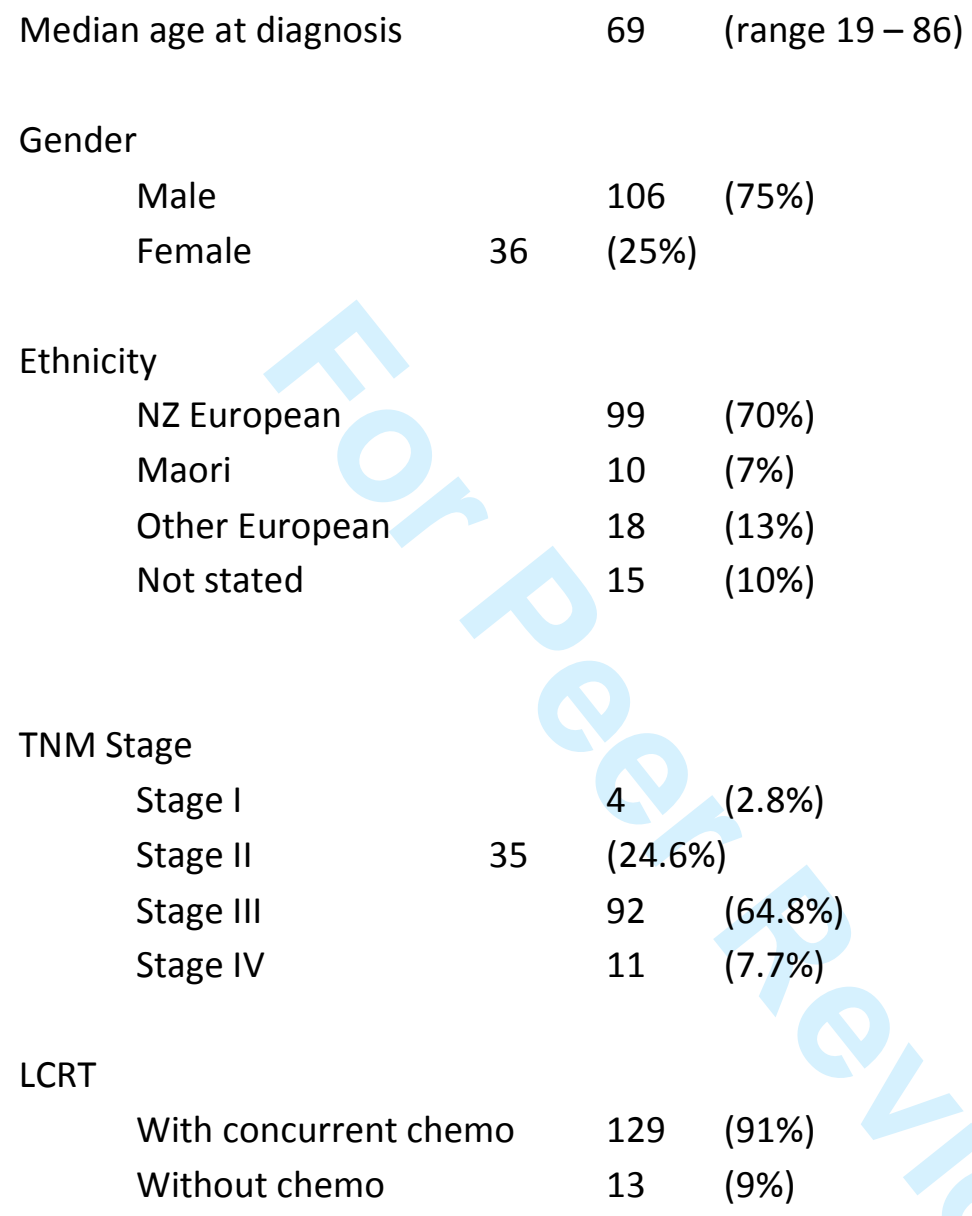


Table 2: Statin and aspirin use during neo-adjuvant long-course radiation

\section{treatment}

\begin{tabular}{|c|c|c|c|c|}
\hline & $\begin{array}{l}\text { On statins } \\
(n=33)\end{array}$ & $\begin{array}{l}\text { Not on } \\
\text { statins } \\
(n=109)\end{array}$ & $\begin{array}{l}\text { On aspirin } \\
(n=35)\end{array}$ & $\begin{array}{l}\text { Not on } \\
\text { aspirint } \\
(n=106)\end{array}$ \\
\hline \multicolumn{5}{|l|}{ Gender } \\
\hline Male & 25 (76\%) & 81 (74\%) & $29(83 \%)$ & 76 (72\%) \\
\hline Female & $8(24 \%)$ & $28(26 \%)$ & $6(17 \%)$ & $30(28 \%)$ \\
\hline Median age (range) & $\begin{array}{c}71 \\
(59-84)\end{array}$ & $\begin{array}{c}67 \\
(19-86)\end{array}$ & $\begin{array}{c}72 \\
(54-86)\end{array}$ & $\begin{array}{c}67 \\
(19-86)\end{array}$ \\
\hline \multicolumn{5}{|l|}{ MRI Stage } \\
\hline Stage I & $2(6.1 \%)$ & $2(1.8 \%)$ & $1(2.9 \%)$ & $3(2.8 \%)$ \\
\hline Stage II & $14(42.4 \%)$ & 21 (19.3\%) & 12 (34.3\%) & 23 (21.7\%) \\
\hline Stage III & $16(48.5 \%)$ & 76 (69.7\%) & 20 (57.1\%) & 71 (67\%) \\
\hline Stage IV & $1(3 \%)$ & $10(9.2 \%)$ & $2(5.7 \%)$ & $9(8.5 \%)$ \\
\hline \multicolumn{5}{|l|}{$\begin{array}{l}\text { Concurrent } \\
\text { chemotherapy }\end{array}$} \\
\hline Yes & $28(85 \%)$ & 101 (93\%) & 27 (77\%) & 101 (95\%) \\
\hline No & 5 (15\%) & $8(7 \%)$ & $8(23 \%)$ & $5(5 \%)$ \\
\hline $\begin{array}{l}\text { Maximal bladder } \\
\text { toxicity }\end{array}$ & $14(42.4 \%)$ & 43 (39.4\%) & 11 (31.4\%) & 46 (43.4\%) \\
\hline Grade 0 & 15 (45.5\%) & 47 (43.1\%) & $16(45.7 \%)$ & 45 (42.5\%) \\
\hline Grade 1 & 4 (12.1\%) & 17 (15.6\%) & $8(22.9 \%)$ & 13 (12.3\%) \\
\hline Grade 2 & $0(0 \%)$ & 1 (0.9\%) & $0(0 \%)$ & 1 (0.9\%) \\
\hline $\begin{array}{l}\text { Grade } 3 \\
\text { Unknown }\end{array}$ & $0(0 \%)$ & $1(0.9 \%)$ & $0(0 \%)$ & $1(0.9 \%)$ \\
\hline \multicolumn{5}{|l|}{ Maximal rectal } \\
\hline Grade 0 & 5 (15.1\%) & 35 (32.1\%) & $4(11.4 \%)$ & 36 (34\%) \\
\hline Grade 1 & $22(66.7 \%)$ & 50 (45.9\%) & $23(65.7 \%)$ & 48 (45.3\%) \\
\hline Grade 2 & $4(12.1 \%)$ & 15 (13.8\%) & $4(11.4 \%)$ & 15 (14.2\%) \\
\hline $\begin{array}{l}\text { Grade } 3 \\
\text { Unknown }\end{array}$ & $0(0 \%)$ & 1 (0.9\%) & $0(0 \%)$ & 1 (0.9\%) \\
\hline
\end{tabular}


Figure Legends:

Figure 1. Distribution of maximum rectal toxicity grades during chemoradiation, according to statin use (Spearman R not significant).

Figure 2. Actuarial plot of time to maximum rectal toxicity in patients who had at least grade 2 toxicity. 
1

2

3

4

5

6

7

8

9

10

11

12

13

14

15

16

17

18

19

20

21

22

23

24

25

26

27

28

29

30

31

32

33

34

35

36

37

38

39

40

41

42

43

44

45

46

47

48

49

50

51

52

53

54

55

56

57

58

59

60

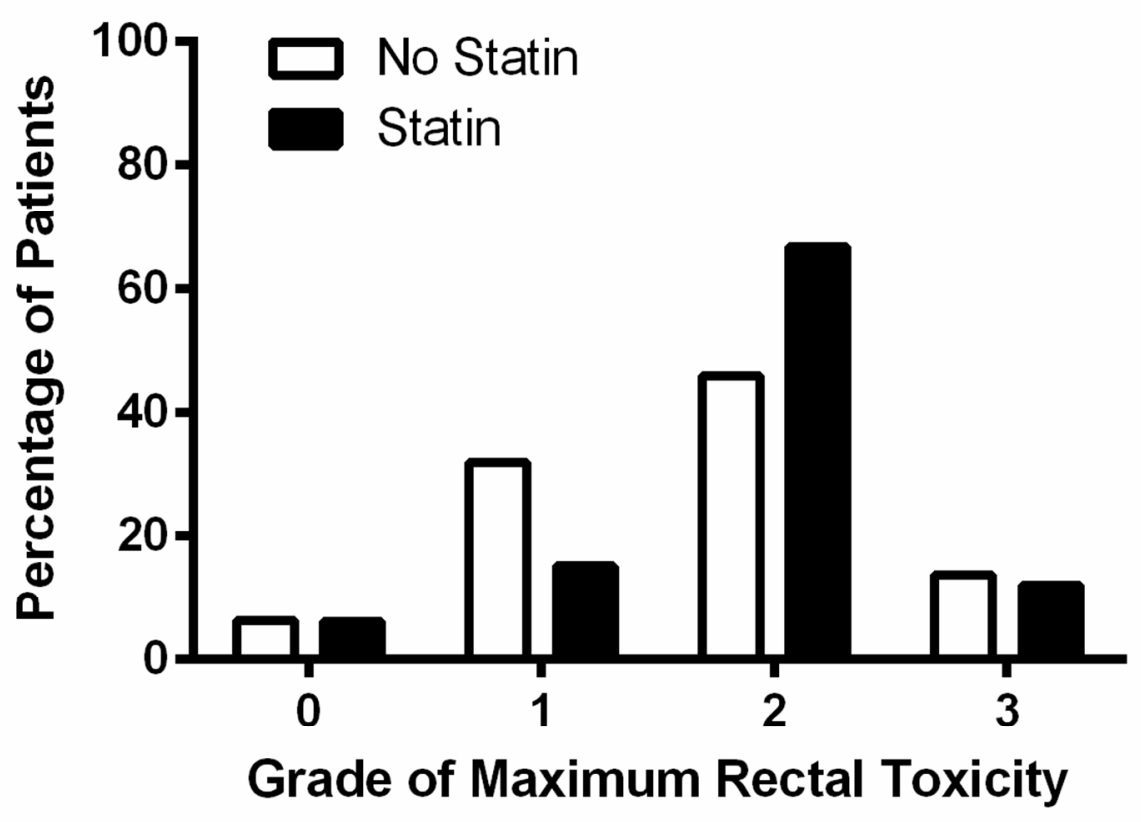

Figure 1. Distribution of maximum rectal toxicity grades during chemoradiation, according to statin use (Spearman R not significant). $106 \times 73 \mathrm{~mm}(300 \times 300 \mathrm{DPI})$ 


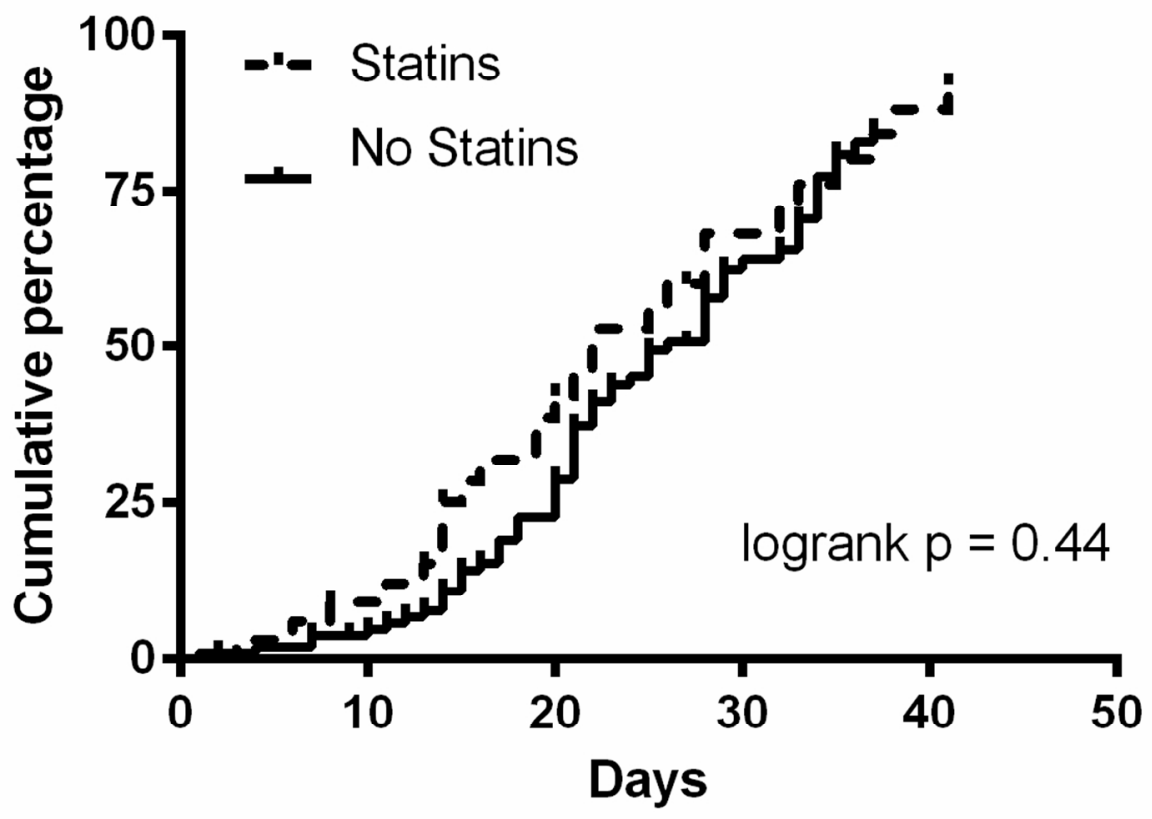

Figure 2. Actuarial plot of time to maximum rectal toxicity in patients who had at least grade 2 toxicity. $105 \times 73 \mathrm{~mm}(300 \times 300 \mathrm{DPI})$ 